\title{
Impactos socioambientais gerados no curtimento do couro no Semiárido Paraibano
}

\author{
Socio-environmental impacts generated in leather leathering in the Semi-arid of Paraíba \\ Impactos socioambientales generados en el curtido del cuero en la Región Semiárida de Paraíba
}

Recebido: 30/07/2021 | Revisado: 03/08/2021 | Aceito: 05/08/2021 | Publicado: 10/08/2021

\author{
Ana Clara Sampaio Meira \\ ORCID: https://orcid.org/0000-0002-2912-4803 \\ Universidade Federal de Campina Grande, Brasil \\ E-mail: ana-clarasm@hotmail.com \\ Romário de Sousa Almeida \\ ORCID: https://orcid.org/0000-0003-3405-6937 \\ Universidade Federal de Lavras, Brasil \\ E-mail: romario_r.s.a@hotmail.com \\ Rubens Barrichello Gomes Barbosa \\ ORCID: https://orcid.org/0000-0002-6806-0590 \\ Universidade Federal de Viçosa, Brasil \\ E-mail: rubens.barbosa@ufv.br \\ Débora Rafaelly Soares Silva \\ ORCID: https://orcid.org/0000-0002-7727-9535 \\ Universidade Federal de Campina Grande, Brasil \\ E-mail: deborarafaelly@yahoo.com.br \\ Kaique Muniz Álvares de Lima \\ ORCID: https://orcid.org/0000-0001-5999-6357 \\ Universidade Federal de Campina Grande, Brasil \\ E-mail: kay.muniz@hotmail.com \\ Luzia Batista Moura \\ ORCID: https://orcid.org/0000-0002-3721-2328 \\ Universidade Federal de Campina Grande, Brasil \\ E-mail: luziabmoura94@gmail.com
}

\section{Resumo}

A atividade do curtume do couro pode acarretar sérios danos nos âmbitos físico, ambiental e social. A presente pesquisa se propõe a identificar os impactos positivos e/ou negativos gerados por meio do processamento do curtimento do couro no Distrito de Ribeira, no município de Cabaceiras - Paraíba. Para tanto, o curtume Miguel de Sousa Meira do Distrito de Ribeira, foi escolhido tendo em vista sua importância econômica e social no âmbito local, bem como, pelo possível potencial de geração de impactos em termos socioambientais. Foi definido um raio de $1 \mathrm{~km}$ ao redor da cooperativa, obtendo-se assim um total de 44 residências próximas ao empreendimento. Além disso, foi aplicado um questionário, a partir de uma entrevista semiestruturada junto à comunidade do entorno da cooperativa, a finalidade desse instrumento foi avaliar a percepção da população acerca dos impactos socioambientais ocasionados por esse empreendimento. Os dados foram tabulados em planilha do Excel 2019® e analisados de forma qualitativa e quantitativa. De acordo com os resultados obtidos, a maior parte dos entrevistados apontaram que a produção do curtume do couro apresentou impactos negativos, como: gasto excessivo com água, contaminação do solo, além do desmatamento de espécies nativas. Nesse contexto, o grau de proximidade das residências foi um fator decisivo na classificação desses impactos, principalmente devido ao mau cheiro e poluição visual que essa atividade ocasionava.

Palavras-chave: Produção de couro; Geração de resíduos; Qualidade ambiental.

\begin{abstract}
The activity of the leather tanning can cause serious damage in the physical, environmental and social spheres. This research proposed to identify the positive and / or negative impacts generated by processing the leather tanning in the District of Ribeira, in the municipality of Cabaceiras - Paraíba. To this end, the Miguel de Sousa Meira tannery in the district of Ribeira was chosen in view of its economic and social importance at the local level, as well as the potential for generating socio-environmental impacts. A radius of $1 \mathrm{~km}$ was defined around the cooperative, thus obtaining a total of 44 residences close to the enterprise. Furthermore, a questionnaire was applied, based on a semi-structured interview with the community surrounding the cooperative, the purpose of this instrument was to assess the population's perception of the socio-environmental impacts caused by this enterprise. The data were tabulated in an Excel $2019 \circledR$ spreadsheet and analyzed qualitatively and quantitatively. According to the results obtained, most of the interviewees pointed out that the production of leather tanneries had negative impacts, such as: excessive spending on water, soil contamination, in addition to deforestation of native species. In this context, the degree of proximity to the
\end{abstract}


homes was a decisive factor in the classification of these impacts, mainly due to the bad smell and visual pollution that this activity caused.

Keywords: Leather production; Waste generation; Environmental quality.

\begin{abstract}
Resumen
La actividad de curtido de cuero puede causar graves daños físicos, medioambientales y sociales. Esta investigación tiene como objetivo identificar los impactos positivos y/o negativos generados por el procesamiento del curtido de cuero en el Distrito de Ribeira, en el Municipio de Cabaceiras - Paraíba. Para esto, se eligió la curtiduría Miguel de Sousa Meira, en el Distrito de Ribeira, por su importancia económica y social a nivel local, así como por su potencial para generar impactos socioambientales. Se definió un radio de $1 \mathrm{~km}$ alrededor de la cooperativa, obteniendo así un total de 44 hogares cercanos a la empresa. Además, se aplicó un cuestionario, a partir de una entrevista semiestructurada con la comunidad del entorno de la cooperativa, el propósito de este instrumento fue evaluar la percepción de la población sobre los impactos sociales y ambientales causados por este emprendimiento. Los datos se tabularon en la planilla Excel 2019® y se analizaron cualitativa y cuantitativamente. De acuerdo con los resultados obtenidos, la mayoría de los entrevistados indicaron que la producción de curtidos de cuero presenta impactos negativos, tales como: gasto excesivo de agua, contaminación del suelo, además de la deforestación de especies nativas. En este contexto, el grado de proximidad a las viviendas fue un factor decisivo para clasificar estos impactos, principalmente por el mal olor y la contaminación visual que provoca esta actividad.
\end{abstract}

Palabras clave: Producción de cuero; Generación de residuos; Calidad ambiental.

\title{
1. Introdução
}

A indústria de couro participa de diferentes cadeias produtivas. Ela depende da pecuária de corte e dos frigoríficos, que fornecem sua principal matéria-prima. A indústria é composta especialmente dos curtumes, que fabricam seu produto final (couro), e fornece para diferentes indústrias, que utilizam o couro como um de seus insumos: calçados e artefatos, vestuário, móveis e automobilística (ABDI, 2011).

De acordo com Teixeira (2018), o curtume do couro consiste nas operações do processamento do couro cru, no qual utiliza-se um líquido específico para minimizar seus efeitos e/ou cessar seu aspecto orgânico. Podem ser classificados de acordo com suas operações, sendo dividido em curtume integrado, quando realiza-se todas as etapas de beneficiamento das

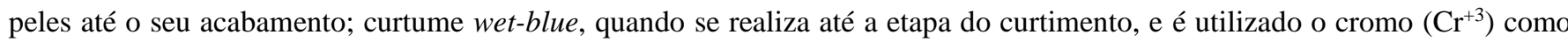
principal reagente; curtume semiacabado, quando utilizam o couro proveniente do curtume wet-blue e o torna em couro semiacabado; e curtume de acabamento, onde se realiza as etapas de acabamento no couro semiacabado (Angeli, 2021).

Para Meira (2011), o Nordeste brasileiro é referência nacional no curtimento de peles, principalmente de caprinos e ovinos, tendo o município de Cabaceiras localizado no interior da Paraíba como destaque. Esta região apresenta um elevado potencial produtivo desses animais, o que torna uma estratégia econômica que serve para driblar algumas adversidades do local, como a escassez hídrica. Ainda, de acordo com o autor, o Nordeste apresenta alto potencial para produtos derivados das peles de pequenos ruminantes domésticos, apresentando também condições favoráveis para produção de calçados e vestuários em quantidades suficientes para suprir a demanda interna e gerar excedentes exportáveis.

Como qualquer empreendimento que necessita de meios naturais para sua atuação, a produção de peles nos curtumes gera inúmeros impactos ambientais, gerando altas quantidades de resíduos sólidos e líquidos, caracterizado por altas e variáveis concentrações de poluentes complexos, como matéria orgânica, nitrogênio, sólidos suspensos, turbidez, metais pesados, cor intensa, além de teores elevados de salinidade (Wu et al., 2015; Tamersit, Bouhidel \& Zidani, 2018; Sawalha et al., 2019). Jiang et al. (2016) destaca o efeito nocivo que a falta de tratamento adequado para estes resíduos pode causar tanto para o meio ambiente, quanto para a saúde humana.

O município de Cabaceiras vem se tornando referência no curtimento do couro, principalmente no que tange as questões ambientais, por utilizarem a casca do angico branco (Anadenanthera colubrina) no processo de curtimento, ao invés do cromo, que é um produto químico com alta capacidade poluidora. Entretanto, esta alternativa adotada no município é uma 
Research, Society and Development, v. 10, n. 10, e279101018894, 2021

(CC BY 4.0) | ISSN 2525-3409 | DOI: http://dx.doi.org/10.33448/rsd-v10i10.18894

medida isolada para mitigar os efeitos negativos que podem ocorrer durante uma das etapas de curtimento do couro, sendo extremamente importante pontuar os impactos positivos e/ou negativos que podem ser gerados para a comunidade que circunda a área de abrangência desse empreendimento. Diante disso, a pesquisa tem por objetivo identificar os impactos positivos e/ou negativos gerados por meio do processamento do curtimento do couro no Distrito de Ribeira, no município de Cabaceiras - Paraíba.

\section{Metodologia}

\section{1 Área de estudo}

A Cooperativa dos Curtidores e Artesãos da Ribeira, ARTEZA, localiza-se no Distrito de Ribeira na zona rural de Cabaceiras, Paraíba. A mesma possui 75 associados, beneficiando aproximadamente 200 famílias, segundo informações do gerente Luís Meira. A cidade está situada na mesorregião da Borborema e na microrregião do Cariri, e apresenta uma área de 400,22 $\mathrm{km}^{2}$ (AESA, 2011).

Figura 1. Localização do município de Cabaceiras, Paraíba.

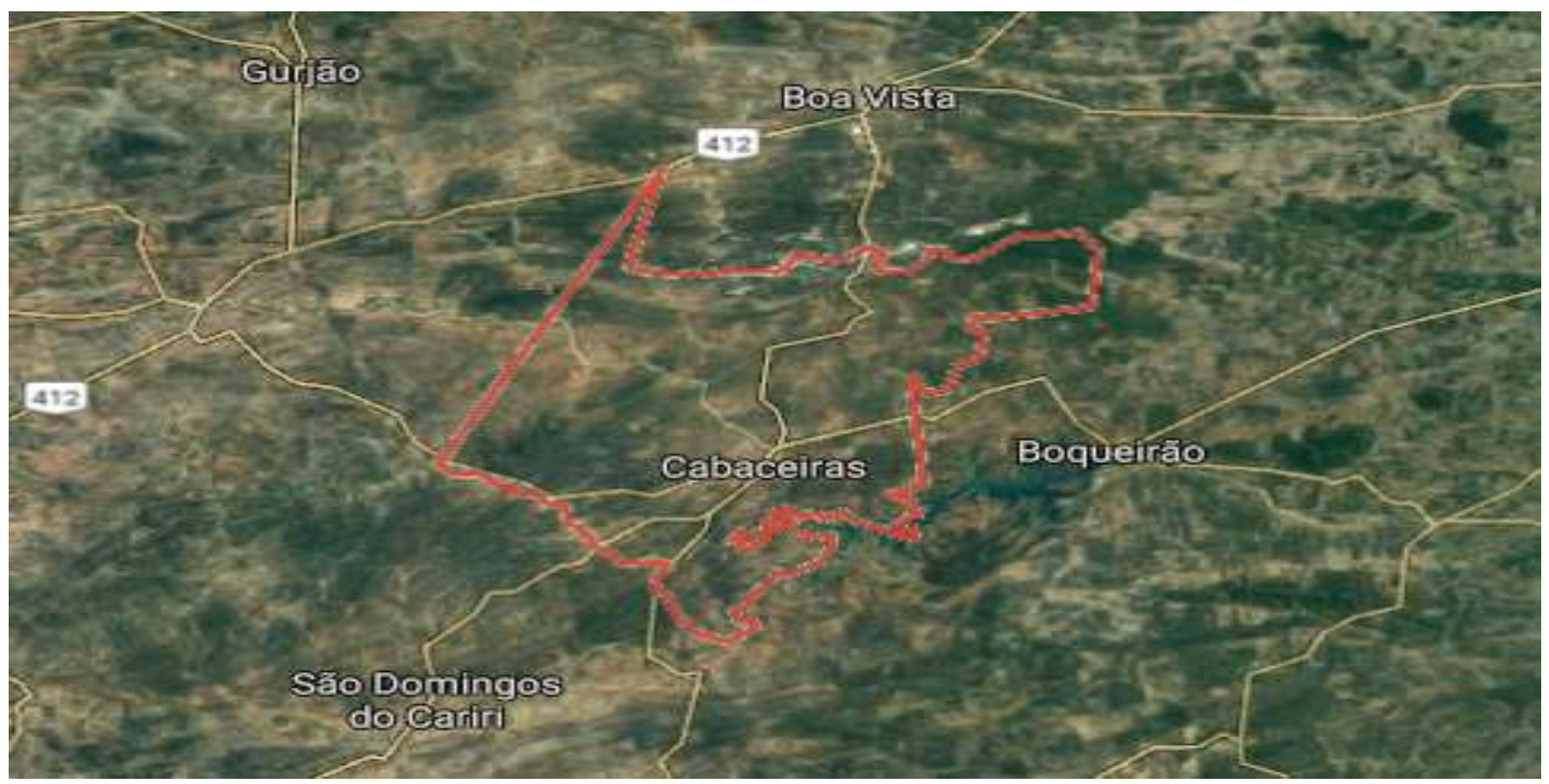

Fonte: Google Mapas (2020).

Na Figura 1, observa-se a localização do município de Cabaceiras, que se limita com os municípios de São João do Cariri, São Domingos do Cariri, Barra de São Miguel, Boqueirão e Boa Vista, no Estado da Paraíba.

\subsection{Clima}

O município é conhecido por apresentar o menor índice pluviométrico do Brasil e conforme Sousa (2007), o clima da região é caraterizado como quente e seco, apresentando temperaturas médias anuais em torno de $24,5^{\circ} \mathrm{C}$. Possui distribuição irregular das chuvas em curtos períodos com estação seca prolongada e uma média pluviométrica de $400 \mathrm{~mm}$ por ano. 


\subsection{Bacia Hidrográfica}

Para o autor Francisco (2010), a maior parte da região do Cariri do estado da Paraíba está compreendido na área da bacia do açude de Boqueirão, que compreende duas bacias contribuintes a montante, a do Alto Paraíba e a do rio Taperoá.

\subsection{Solo}

Em relação aos solos da região, apresentam neossolos litólicos eutróficos, afloramentos de rochas formando associações, principalmente com solos neossolos litólicos eutróficos, além de inclusões, em pequenas parcelas, de planossolo nátrico sálico, de neossolo flúvico eutrófico e de vertissolo cromado (Francisco, 2010).

\subsection{Vegetação}

De acordo com Sousa (2007), a vegetação predominante é a caatinga hiperxerófila. As espécies mais encontradas em campo são: jurema (Mimosa tenuiflora (Willd.) Poiret.), marmeleiro (Croton sonderianus Muell. Arg.), pereiro (Aspidosperma pyrifolium Mart.), mandacaru (Cereus jamacaru P.DC.) e xique-xique (Pilocereus gounelliei (Webwer) Byl. Et Rowl.).

\subsection{Fauna}

Os répteis e anfíbios têm destaque na fauna da região, no qual são conhecidas 97 espécies de répteis e 45 de anfíbios. Em relação às aves, essas podem ultrapassar 200 espécies em uma mesma localidade, enquanto para os mamíferos da região, faz-se necessário a realização de mais estudos (Leal, 2003).

\subsection{Atividades econômicas}

Atualmente o município conta com duas principais atividades econômicas: o turismo e a caprinocultura. Conforme Alves (2008), a cidade possui um belo atrativo natural, com destaque para a "Pedra do Pai Mateus" que apresenta um valor cênico reconhecido nacional e internacionalmente, além de ser um atrativo cultural, destacando a "Festa do Bode Rei", que se encontra no calendário de eventos turísticos da Paraíba. Segundo Meira (2011), a caprinocultura passou a ser desenvolvida na localidade devido à crise da cultura do alho, fazendo com que os produtores da região investissem nessa atividade comercial por apresentar elevado potencial econômico.

\subsection{Produção do Couro}

O processo de curtimento do couro é bastante complexo e abrange diversas etapas, conforme verificado nos esquemas abaixo (Class \& Maia, 1994, apud Pacheco, 2015), conforme Figuras 2 e 3. 
Figura 2. Operação de ribeira, curtimento e acabamento molhado.

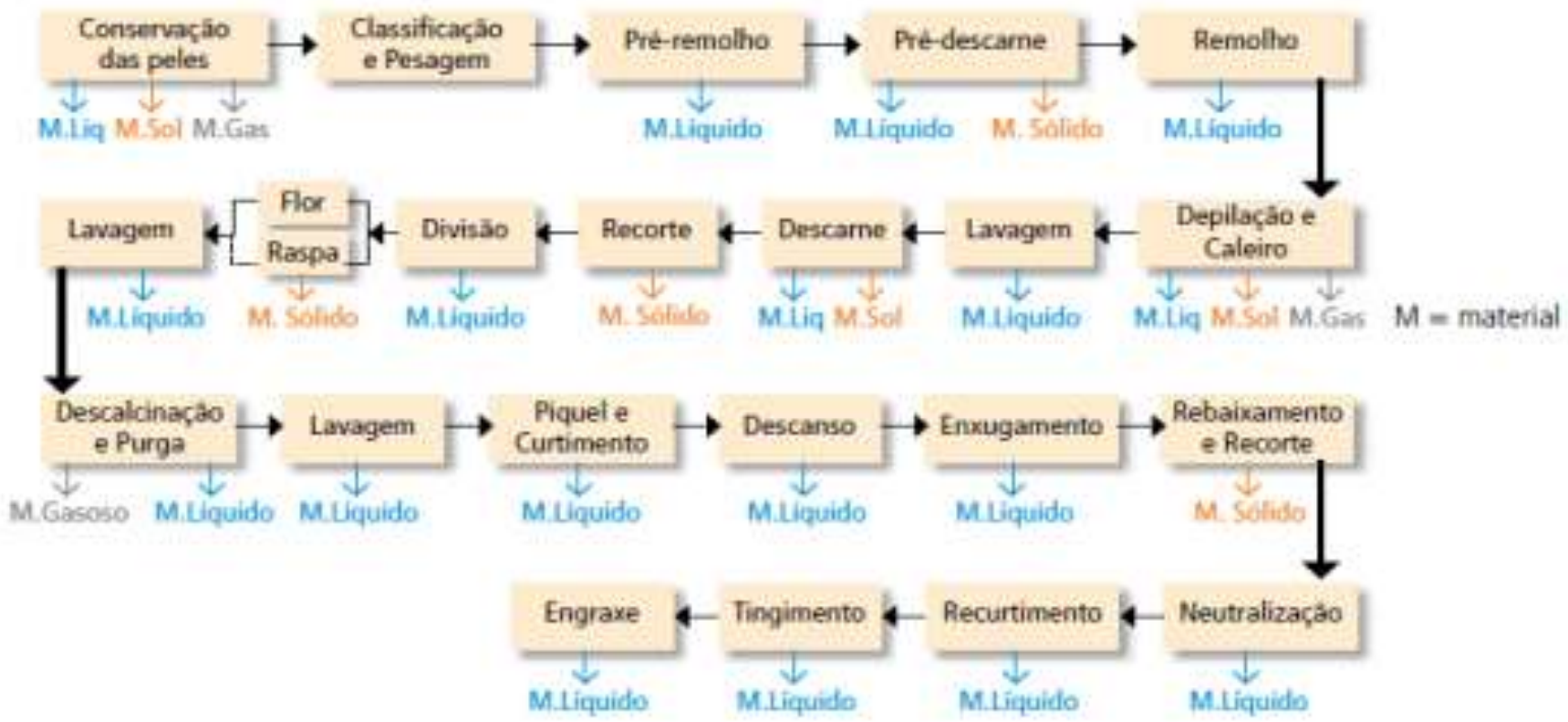

Fonte: Pacheco (2015), adaptado de Claas \& Maia (1994).

Figura 3. Operação de pré-acabamento e acabamento.

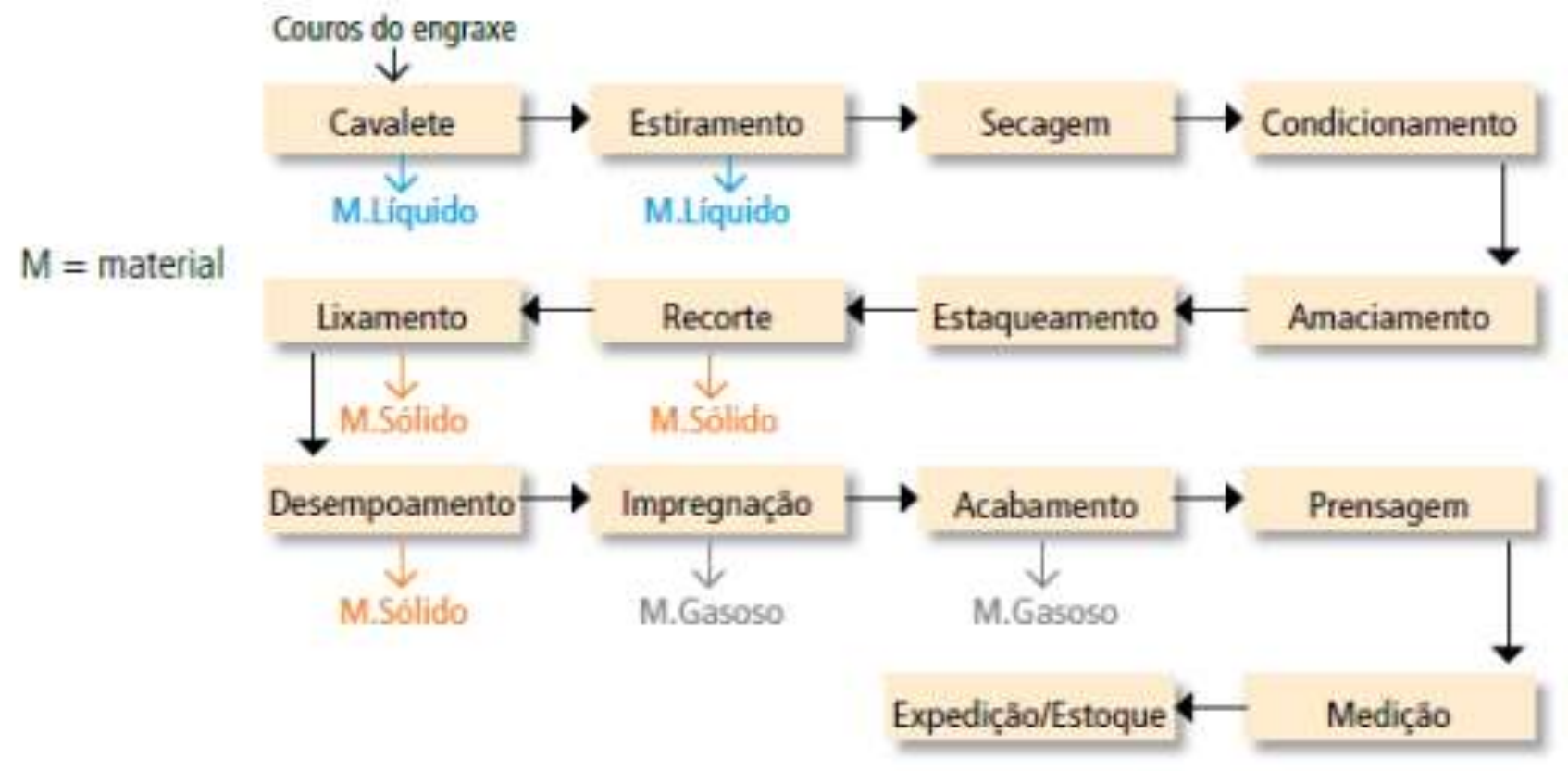

Fonte: Pacheco (2015); adaptado de Claas \& Maia (1994).

Na Figura 2, observa-se o esquema dos processos iniciais dentro de um curtume, em que a pele passa por várias lavagens afim de retirar todos os resíduos presentes na pele. O processo de curtimento se inicia na etapa "píquel e curtimento", onde ocorre a transformação em si da pele para o couro. Na Figura 3, está esquematizado o processo de acabamento do couro, com etapas importantes como o amaciamento e o lixamento.

\subsection{Método de avaliação dos dados}

O curtume Miguel de Sousa Meira do distrito de Ribeira, Cabaceiras, foi escolhido tendo em vista sua importância 
econômica e social no âmbito local, bem como pelo alto potencial de geração de impactos em termos socioambientais. Foi delimitado como área de abrangência do estudo, o raio de $1 \mathrm{~km}$ ao redor da cooperativa, obtendo-se assim um total de 44 residências localizadas nas imediações do empreendimento. As residências avaliadas, encontram-se situadas em diferentes pontos estratégicos, com o intuito de averiguar a influência dos impactos em função do local em que residem os entrevistados.

Para o desenvolvimento da referida pesquisa, a metodologia adotada foi a descritiva, que conforme Vergara (2000), consiste na exposição das características de determinada população ou fenômeno. O instrumento da pesquisa baseia-se na aplicação de um questionário sob a forma de entrevista semiestruturada junto à comunidade circunvizinha da cooperativa pertencente ao município de Cabaceiras, de modo, a avaliar a percepção da comunidade acerca dos impactos físicos, biológicos e socioeconômicos ocasionados por esse empreendimento.

$\mathrm{Na}$ elaboração dos questionamentos, foram elencados os principais impactos ocasionados no processo de curtimento do couro, conforme proposto por Brito (2013) descritos na Tabela 1. Fez-se o uso de questões fechadas, tendo como opções respostas dicotômicas, no qual o respondente deveria optar por umas das opções (sim ou não), que foram previamente apresentadas.

Tabela 1. Principais impactos ocasionados no processo de curtimento do couro.

\begin{tabular}{cc}
\hline Meio & Impactos \\
\hline \multirow{2}{*}{ Físico } & Gasto de água \\
\cline { 2 - 2 } & Contaminação do solo \\
\hline Biológico & Desmatamento de espécie nativa (Angico) \\
\hline Socioeconômico & Aumento da economia local \\
\cline { 2 - 2 } & Diminuição do êxodo rural \\
\hline
\end{tabular}

Fonte: Elaborado pelos autores com base em Brito (2013).

Os moradores foram previamente esclarecidos sobre o objetivo do estudo, recebendo informações pertinentes acerca da procedência, finalidade, assunto tratado e contato dos pesquisadores. Posteriormente, os moradores que concordaram em participar da pesquisa foram entrevistados. As entrevistas foram realizadas nos finais de semana, uma vez que era mais provável que os moradores estivessem em suas residências, além de possuírem maior disponibilidade de tempo.

Em relação aos entrevistados, foi garantido aos mesmos o anonimato no que tange a sua identidade, para que pudessem responder o questionário sem nenhum tipo de constrangimento, sendo caracterizados socialmente com relação ao gênero, faixa etária e nível de escolaridade. Para definição dos procedimentos metodológicos e análise dos dados, utilizou-se como referenciais, as abordagens de Köche (2011) e Pereira et al. (2018). Os dados foram tabulados em planilha eletrônica do Excel $2019 \circledast$ e analisados de forma qualitativa e quantitativa.

\section{Resultados e Discussão}

A Figura 4 corresponde ao percentual dos entrevistados com relação ao gasto excessivo de água para a produção do curtimento do couro sob a visão da comunidade vizinha. 
Figura 4. Percepção dos entrevistados em relação ao gasto excessivo de água no curtimento do couro.

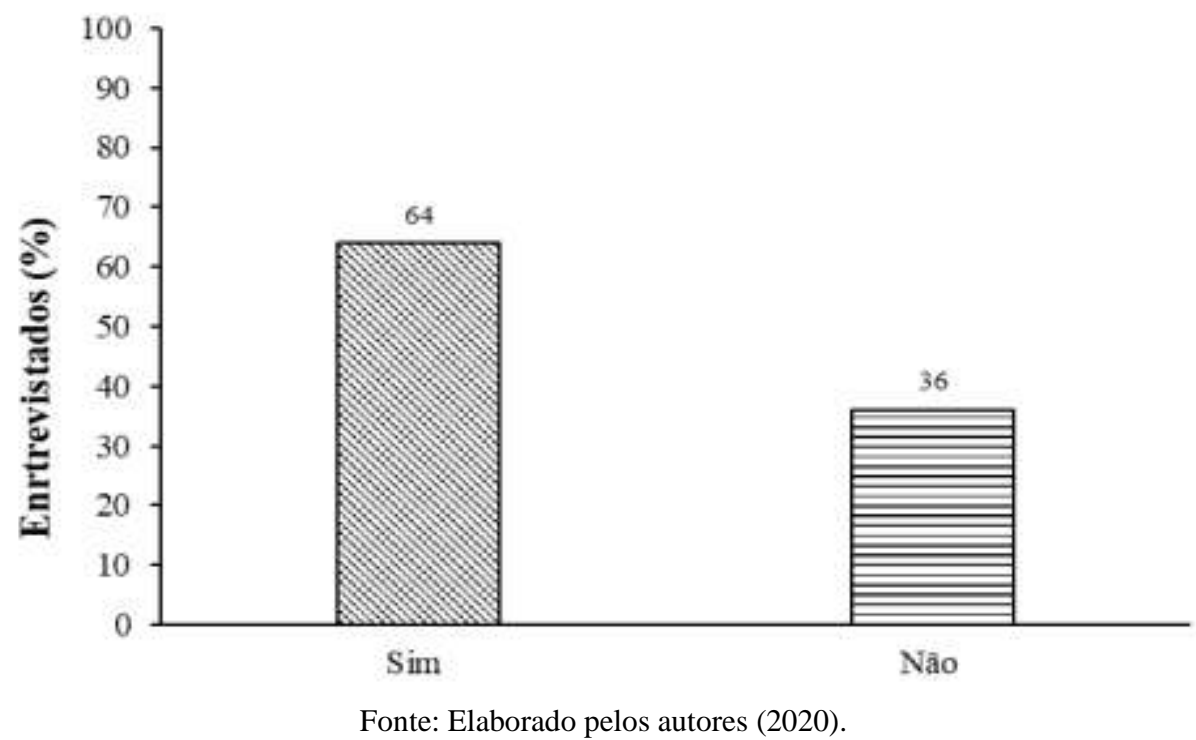

Constatou-se que, para maioria dos entrevistados (64\%) há gasto excessivo de água durante o processo de curtimento do couro. Toso (2021), ressalta a quantidade excessiva de água utilizada nos curtumes, associando o uso de água de um curtume de médio porte ao de uma população de 10.500 pessoas, com $1.900 \mathrm{~m}^{3}$ consumidos diariamente. Santos et al. (2020), afirma que a indústria do couro utiliza quantidades elevadas de água, principalmente nas etapas de limpeza e no curtimento das peles, sendo o curtimento responsável por cerca de $90 \%$ dos resíduos líquidos gerados pelos curtumes. Silva et al. (2020), enfatiza a problemática do uso excessivo da água em processos industriais localizados em regiões mais secas, a exemplo de Cabaceiras, onde se encontra o curtume estudado no presente trabalho, caracterizando a atividade como não sustentável.

Santos et al. (2020), destaca algumas alternativas para aperfeiçoar a utilização de água em curtumes, como a reutilização da água utilizada nas lavagens, tratamento do resíduo liquido gerado no curtimento. De forma complementar, Faria (2016) sugere uma rotina de manutenção de equipamentos e das linhas de produção, uma vez que, falhas podem acarretar em perdas de água, banhos mais curtos, assim como também a reutilização de água dos processos de limpeza.

A Figura 5 aborda os problemas relacionados à contaminação do solo resultantes do curtume do couro sob a perspectiva da população circunvizinha. 
Figura 5. Problemas com contaminação do solo por meio do processamento do curtimento do couro.

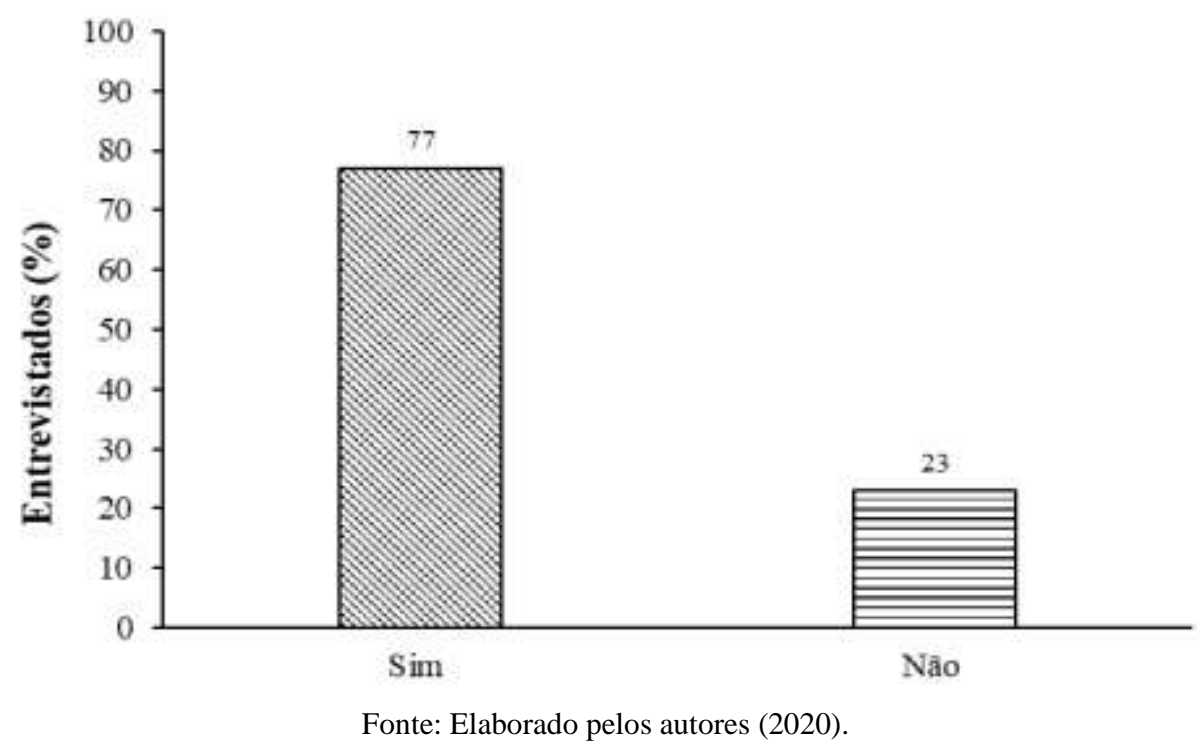

Na percepção da maioria da vizinhança do curtume, $77 \%$ dos entrevistados, apontaram que o processamento do couro no empreendimento do município contribui para a contaminação dos solos devido ao líquido que é utilizado no curtume ser descartado diretamente no solo sem nenhum tipo de tratamento. Nesse contexto, Duarte (2011), diagnosticando impactos ambientais decorrentes do beneficiamento de pele no município de Cabaceiras-PB, observou-se que durante as visitas ao local, foi verificado que muitos resíduos são lançados ao solo, comumente próximo onde são gerados ou dentro do próprio terreno dos curtumes, acarretando assim, a contaminação de toda aquela área, aumentando a proliferação do mau cheiro, bem como a poluição visual. Outro problema observado na cooperativa foi o descarte inadequado de cal realizada na fase inicial do curtimento para facilitar a retirada do pelo. Nesse sentido, Aquim (2008) aponta em seu estudo que a cal era uma substância química que provocava contaminação no solo devido ao lançamento ao entorno dos curtumes.

A Figura 6 representa o percentual dos entrevistados com relação ao desmatamento de espécies nativas ao entorno da cooperativa sob a ótica da população vizinha.

Figura 6. Avaliação do desmatamento de espécies nativas para o curtume do couro.

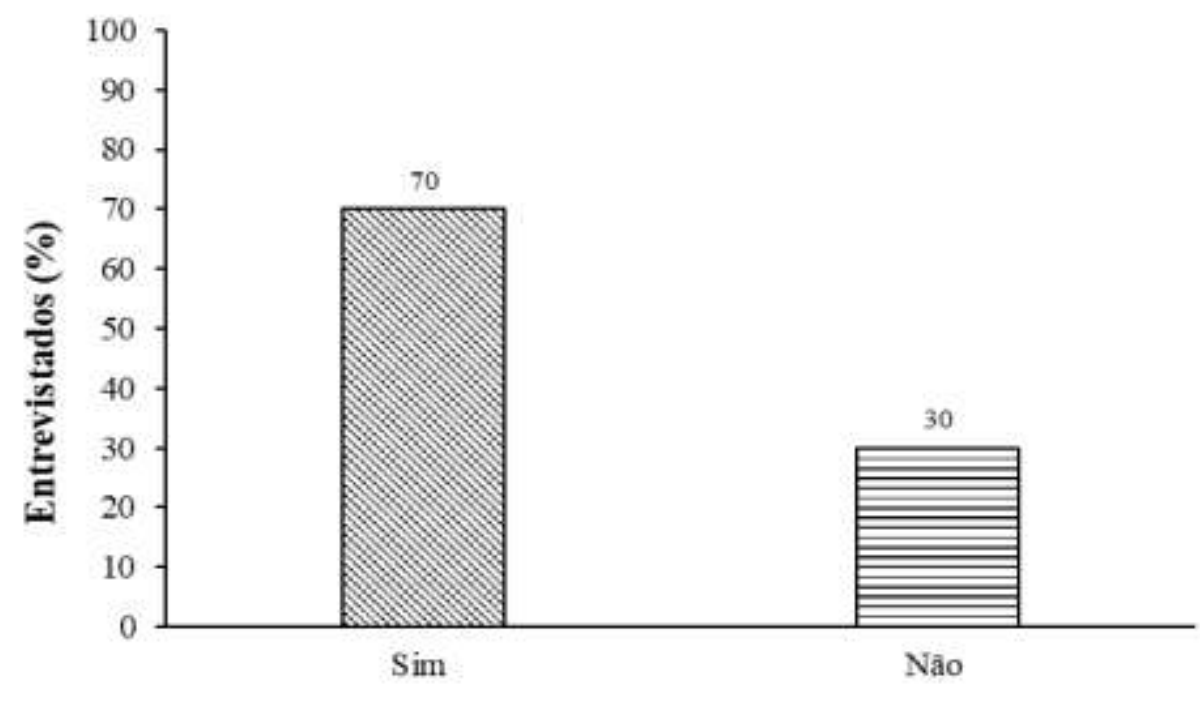

Fonte: Elaborado pelos autores (2020). 
Para $70 \%$ dos entrevistados, o curtume potencializa o desmatamento de espécies nativas ao entorno do empreendimento, uma vez que no processo de curtimento é utilizado o angico e que sua extração tem gerado o desmatamento desta espécie na área em estudo. Conforme Olegário (2019), o angico-vermelho (Anadenanthera colubrina - Vell. Brenan var. cebil (Gris.) Alts.), é a única espécie nativa da região do Nordeste que produz tanino vegetal utilizado no curtimento.

De acordo com Matos Júnior et al. (2017), o consumo de cascas de angico-vermelho no município de Cabaceiras é de aproximadamente 200 toneladas por ano. Conforme Fonseca (2017), a utilização de casca de angico no curtimento, apesar de diminuir a quantidade de produtos químicos no beneficiamento de peles, apresenta pontos negativos, uma vez que é responsável pelo desmatamento do angico na região. Para Silva et al. (2020), por não ser realizado um planejamento e um controle da retirada das cascas de angico, a sua utilização no curtimento é caracterizada como uma prática não sustentável, sugerindo um estudo da área onde a espécie é retirada para um possível planejamento da atividade. Para tanto, Duarte (2011) recomenda o plantio de novas mudas, visando diminuir a probabilidade de extinção da A. colubrina.

A Figura 7 abrange a questão relacionada à melhoria da economia da região resultantes da produção do curtimento do couro na cooperativa sob a visão da população circunvizinha.

Figura 7. Melhoria da economia da região mediante perspectiva da população vizinha.

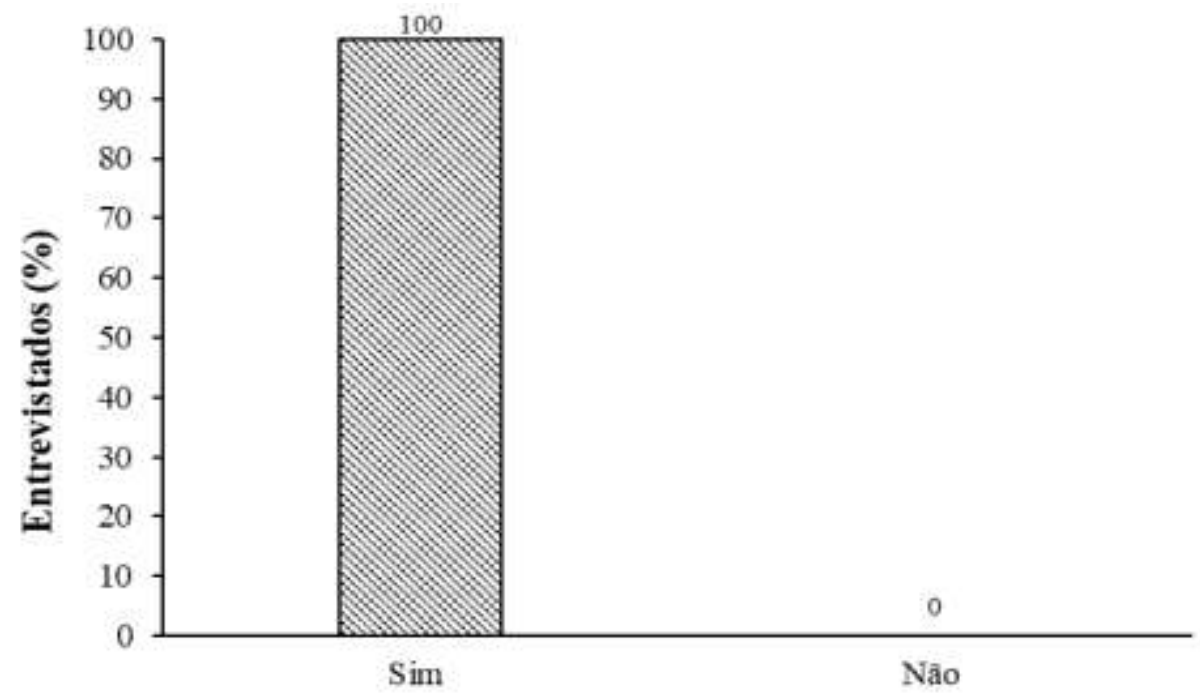

Fonte: Elaborado pelos autores (2020).

Todos os entrevistados afirmaram que o empreendimento coopera para melhoria da economia na região mediante implantação da cooperativa no município de Cabaceiras-PB. O curtume tem propiciado à dinamização da economia por meio da empregabilidade de diversos jovens que tem como primordial fonte de renda o trabalho no artesanato do couro, fabricando muitos produtos que são exportados para vários estados brasileiros e não somente no Nordeste, como também, para o Centro Sul do país (Meira, 2011). Duarte (2011) revela que a principal atividade econômica da região e de comunidades vizinhas é o curtimento do couro de caprinos e bovinos, além da confecção de artefatos em couro, como: chapéus, bolsas, carteiras, dentre outros. Para o autor, nos últimos anos o município de Cabaceiras-PB obteve um aumento significativo devido aos incentivos empregados neste setor, proporcionando assim, o sustento de quase toda a população.

A Figura 8 mostra o percentual das pessoas entrevistadas no que tange a diminuição do êxodo rural, conforme implantação da cooperativa do curtimento do couro sob a perspectiva da população vizinha. 
Figura 8. Avaliação da diminuição do êxodo rural sob o olhar da população.

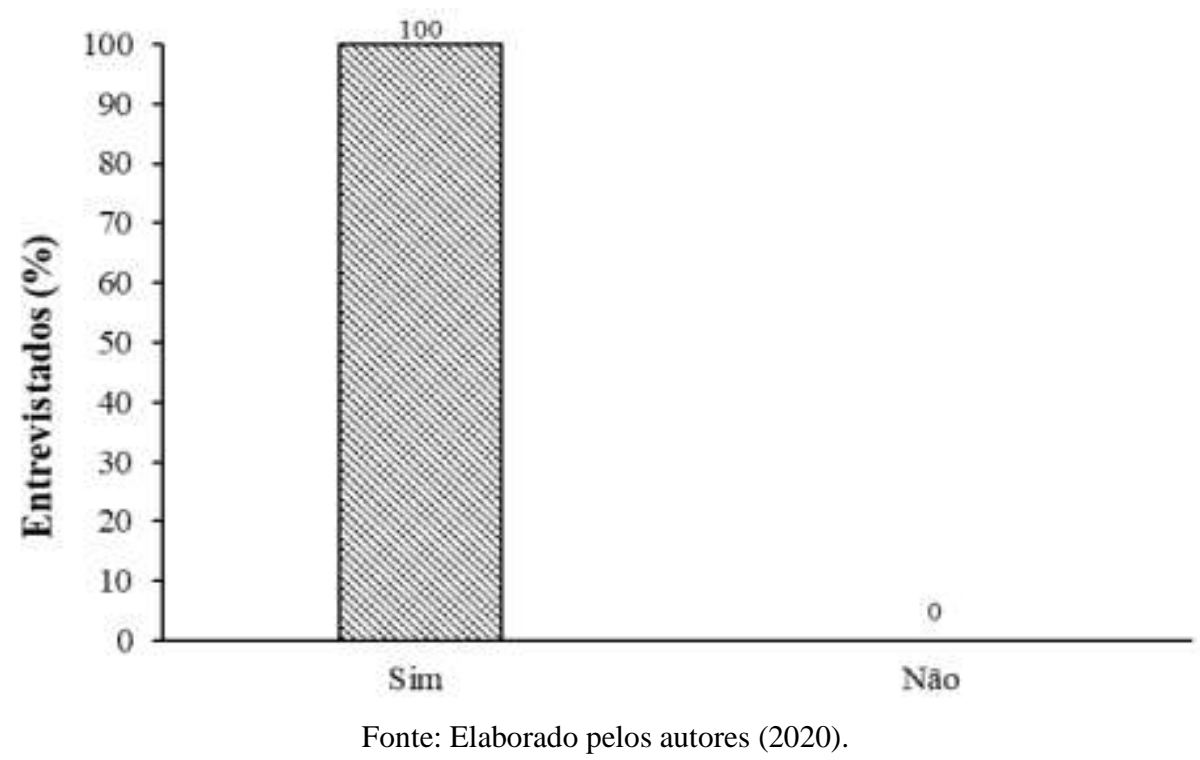

Os entrevistados foram unânimes ao afirmar que a implantação da cooperativa em Cabaceiras-PB contribui para a diminuição do êxodo rural no município. Mediante Duarte (2011), essa atividade traz consigo impactos benéficos para aquelas comunidades onde estão inseridos esses curtumes. Estes impactos estão associados a uma atividade que verticaliza a produção, propiciando oportunidades aos moradores de permanecerem juntos a sua família, e consequentemente reduzindo o êxodo rural, que em sua maioria ocasionam problemas socioambientais. Meira (2011) afirma que o desenvolvimento econômico pela atividade do processamento do curtimento do couro, permite a geração de empregos absorvendo como mão-de-obra as famílias que compõe a região e, consequentemente, evitando a migração destas pessoas para outras regiões do país, pois a maior parte da população que migra de uma região para outra, tem como a principal causa questões financeiras.

\section{Conclusão}

A população residente nas proximidades da cooperativa, é composta basicamente por famílias que apresentam baixo poder aquisitivo, com suas atividades essencialmente domésticas ou voltadas para a subsistência, sendo esta, uma característica predominante da população do Semiárido paraibano. De acordo com os resultados obtidos, evidencia-se que a instalação da cooperativa de curtimento do couro contribuiu para o surgimento de impactos negativos, tais como: gasto excessivo de água, contaminação do solo e desmatamento de espécies nativas para as etapas da atividade coureira. Com relação aos impactos positivos, pode-se enfatizar a importância do curtume na melhoria da economia da região como o aumento de empregos, além da diminuição do êxodo rural no município.

Neste estudo ficou evidente a necessidade de um planejamento adequado durante toda a atividade de curtimento do couro, como forma de mitigar os impactos negativos identificados nos setores físicos e biológicos. Portanto, sugere-se para trabalhos futuros, abordagens que visem oferecer alternativas sustentáveis de tratamento da água proveniente do curtimento do couro, bem como, estudos que visem o manejo adequado da espécie utilizada. 


\section{Referências}

ABDI - Agência Brasileira de Desenvolvimento Industrial. (2011). Relatório de Acompanhamento Setorial: Indústria de Couro. Série Cadernos da Indústria ABDI. Brasília, 2011

AESA - Agência Executiva de Gestão das Águas. (2011). Cabaceiras - 2019. Disponível em: http://www.aesa.pb.gov.br/aesa-website/

Alves, J. J., Souza, E. N., \& Araújo, M. A. (2008). Estudo descritivo da tipologia turística do município de Cabaceiras-Paraíba. Caderno Virtual de Turismo, 8 (3), p. 86-103.

Angeli, J. T. S. K. Implicação ambiental no uso do composto de lodo de curtume em aplicação agrícola. (2021). Dissertação (Mestrado em Ciência Ambiental) - Instituto de Energia e Ambiente, Universidade de São Paulo, São Paulo.

Aquim, P. M., Gutterres, M., Mancopes, F., \& Trierweiler, J. O. (2008). Avaliação ambiental e econômica de tecnologias de processamento de peles em couros. Disponível em: https://www.aaqtic.org.ar/congresos/brasil2008/cd/dados/34.pdf

Brito, G. M. (2013). Impactos ambientais gerados pelos curtumes. Disponível em: http://www.coloquiomoda.com.br/anais/Coloquio\%20de\%20Moda\%20\%202013/ARTIGOS-DE-GT/Artigo-GT-Moda-e-Sustentabilidade/Impactos-ambientais-gerados-pelos-curtumes.pdf

Claas, I. C., \& Maia, R. A. M. Manual básico de resíduos industriais de curtume. Porto Alegre: SENAI/RS, 1994.

Duarte, K. L. S. (2011). Diagnóstico dos impactos ambientais decorrentes do beneficiamento de pele. Trabalho de Conclusão de Curso (Engenharia Sanitária e Ambiental). Universidade Estadual da Paraíba.

Faria, W. D. B. (2016). Curtume: uma análise de impactos físicos, bióticos e socioeconômicos. 2016.47 f. Trabalho de Conclusão de Curso (Graduação) — Universidade Tecnológica Federal do Paraná, Apucarana.

Fonseca, J. B. S. (2017). Os impactos socioeconômicos e ambientais do curtume tradicional de Pedra Grande, Tucano, Bahia. Trabalho de Conclusão de Curso (Graduação), Universidade da Integração Internacional da Lusofonia Afro-Brasileira.

Francisco, P. R. M. (2010). Classificação e mapeamento das terras para mecanização do Estado da Paraíba utilizando sistemas de informações geográficas. Dissertação (Mestrado em Manejo de Solo e Água). Universidade Federal da Paraíba.

Jiang, H., Liu, J., \& Han, W. (2016). The status and developments of leather solid waste treatment: A mini-review. Waste Management \& Research, 34 (5), $399-408$.

Köche, J. C. (2011). Fundamentos de metodologia científica: teoria da ciência e iniciação à pesquisa. Petrópolis-RJ: Vozes. Disponível em: http://www.adm.ufrpe.br/sites/ww4.deinfo.ufrpe.br/files/Fundamentos_de_Metodologia_Cienti\%CC\%81fica.pdf

Leal, I. R., Tabarelli, M., \& Silva, J. M. C. (2003). Ecologia e conservação da Caatinga. Recife: UFPE.

Matos Júnior, J. J. L. D. M., Santos, A. T., DIAS, R. T. V., Meira, A. S., \& Nascimento, J. W. B. (2017). Cariri Paraibano: Turismo em Cabaceiras, Pernambuco. Rosa dos Ventos, 9(1), 120-132.

Meira, G. G. (2011). A produção e exportação do artesanato de couro no Distrito da Ribeira de Cabaceiras - PB: como sustentabilidade sócio-econômica. Trabalho de Conclusão de Curso. Universidade Estadual da Paraíba.

Olegário, M. M. M. (2019). Utilização do tanino vegetal para curtimento de peles: revisão bibliográfica. 2019.22 f. Trabalho de Conclusão de Curso (Graduação), Universidade Federal Rural do Semi-Árido.

Pacheco, J. W. F. (2015). Guia técnico ambiental de curtumes. 2.ed. São Paulo: CETESB, 127p.

Pena, A. C., Agustini, C. B., Trierweiler, L. F., \& Gutterres, M. (2020). Influence of period light on cultivation of microalgae consortium for the treatment of tannery wastewaters from leather finishing stage. Journal of Cleaner Production, 263, 121618.

Pereira, A. S., Shitsuka, D. M., Parreira, F. J., \& Shitsuka, R. (2018). Metodologia da pesquisa científica. [free e-book]. Santa Maria/RS. Ed. UAB/NTE/UFSM. Disponível em: https://repositorio.ufsm.br/bitstream/handle/1/15824/Lic_Computacao_Metodologia-Pesquisa-Cientifica.pdf?sequence=1

Santos, P. V. S., \& de Araújo, M. A. (2020). A metodologia de Produção Mais Limpa (P+ L): um estudo de caso em uma indústria de Curtume. Revista Gestão \& Sustentabilidade Ambiental, 9 (1), 524-547.

Sawalha, H., Alsharabaty, R., Sarsour, S., \& Al-Jabari, M. (2019). Wastewater from leather tanning and processing in Palestine: characterization and management aspects. Journal of environmental management, 251, 109596.

Silva, I. F., da Silva, J. T., Silva, G. M., \& de Oliveira Catanha, A. M. (2020). PRÁTICAS SUSTENTÁVEIS E NÃO SUSTENTÁVEIS NA PRODUÇÃO DE SANDÁLIAS DE COURO CAPRINO EM CABACEIRAS-PB. MIX Sustentável, 6(4), 51-60.

Sousa, R. F., Barbosa, M. P., Morais Neto, J. M., \& Fernandes, M. F. (2007). Estudo do processo da desertificação e das vulnerabilidades do município de Cabaceiras-Paraíba. Engenharia Ambiental: Pesquisa e Tecnologia, 4 (1), 89-102.

Tamersit, S., Bouhidel, K. E., \& Zidani, Z. (2018). Investigation of electrodialysis anti-fouling configuration for desalting and treating tannery unhairing wastewater: Feasibility of by-products recovery and water recycling. Journal of environmental management, 207, 334-340.

Teixeira, M. J. M. (2018). O método Taguchi aplicado ao estudo do curtume do couro sem crómio. Dissertação (Mestrado em Engenharia Química), Politécnico do Porto. 
Research, Society and Development, v. 10, n. 10, e279101018894, 2021

(CC BY 4.0) | ISSN 2525-3409 | DOI: http://dx.doi.org/10.33448/rsd-v10i10.18894

Toso, G. S. (2021). Gestão ambiental na indústria do curtume: uma pesquisa bibliométrica. Universidade Estadual Paulista (UNESP). Disponível em: http://hdl.handle.net/11449/213765.

Vergara, S. C. Projetos e relatórios de pesquisa em administração. 3.ed. Rio de Janeiro: Atlas, 2000.

Wu, S., Wallace, S., Brix, H., Kuschk, P., Kirui, W. K., Masi, F., \& Dong, R. (2015). Treatment of industrial effluents in constructed wetlands: challenges, operational strategies and overall performance. Environmental Pollution, 201, 107-120. 